Extra Supplement: Full Fathom Five. A Four-Part Song

Author(s): Shakespeare and Charles Wood

Source: The Musical Times and Singing Class Circular, Vol. 36, No. 632 (Oct. 1, 1895), pp. 14

Published by: Musical Times Publications Ltd.

Stable URL: http://www.jstor.org/stable/3362165

Accessed: 24-06-2016 13:20 UTC

Your use of the JSTOR archive indicates your acceptance of the Terms \& Conditions of Use, available at
http://about.jstor.org/terms

JSTOR is a not-for-profit service that helps scholars, researchers, and students discover, use, and build upon a wide range of content in a trusted digital archive. We use information technology and tools to increase productivity and facilitate new forms of scholarship. For more information about JSTOR, please contact support@jstor.org.

Musical Times Publications Ltd. is collaborating with JSTOR to digitize, preserve and extend access to The Musical Times and Singing Class Circular 
No. 604.

\title{
FULL FATHOM FIVE
}

\author{
A FOUR-PART SONG
}

THE WORDS WRITTEN BY SHAKESPEARE

THE MUSIC COMPOSED BY

\section{CHARLES WOOD.}

London. NOVELlO, EWER AND CO., I, Berners Street (W.), and 80 \& 8r, Queen Street (E.C.); also in New York.
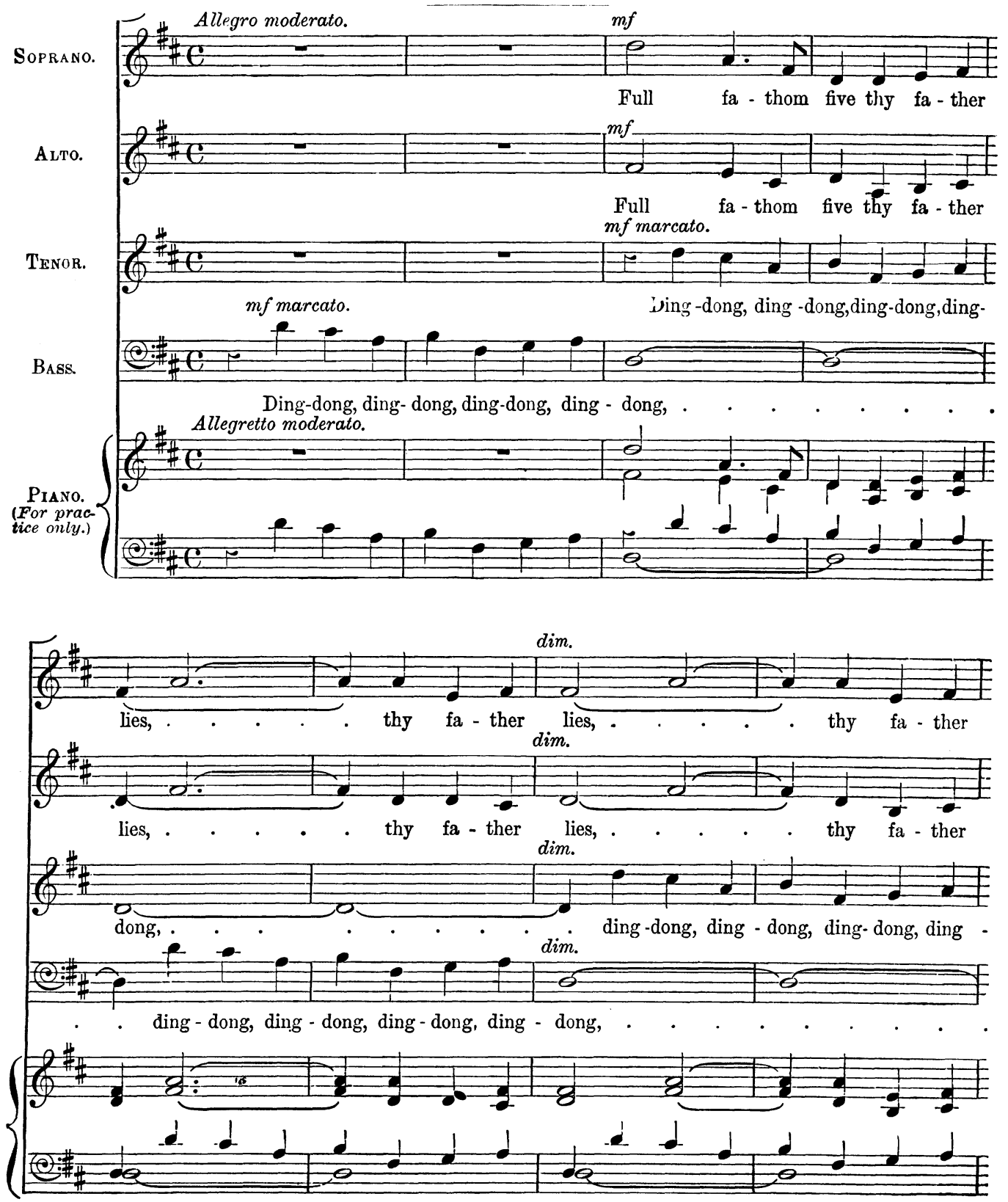

Copyright, 1891, by Novello, Ewer and Co. 

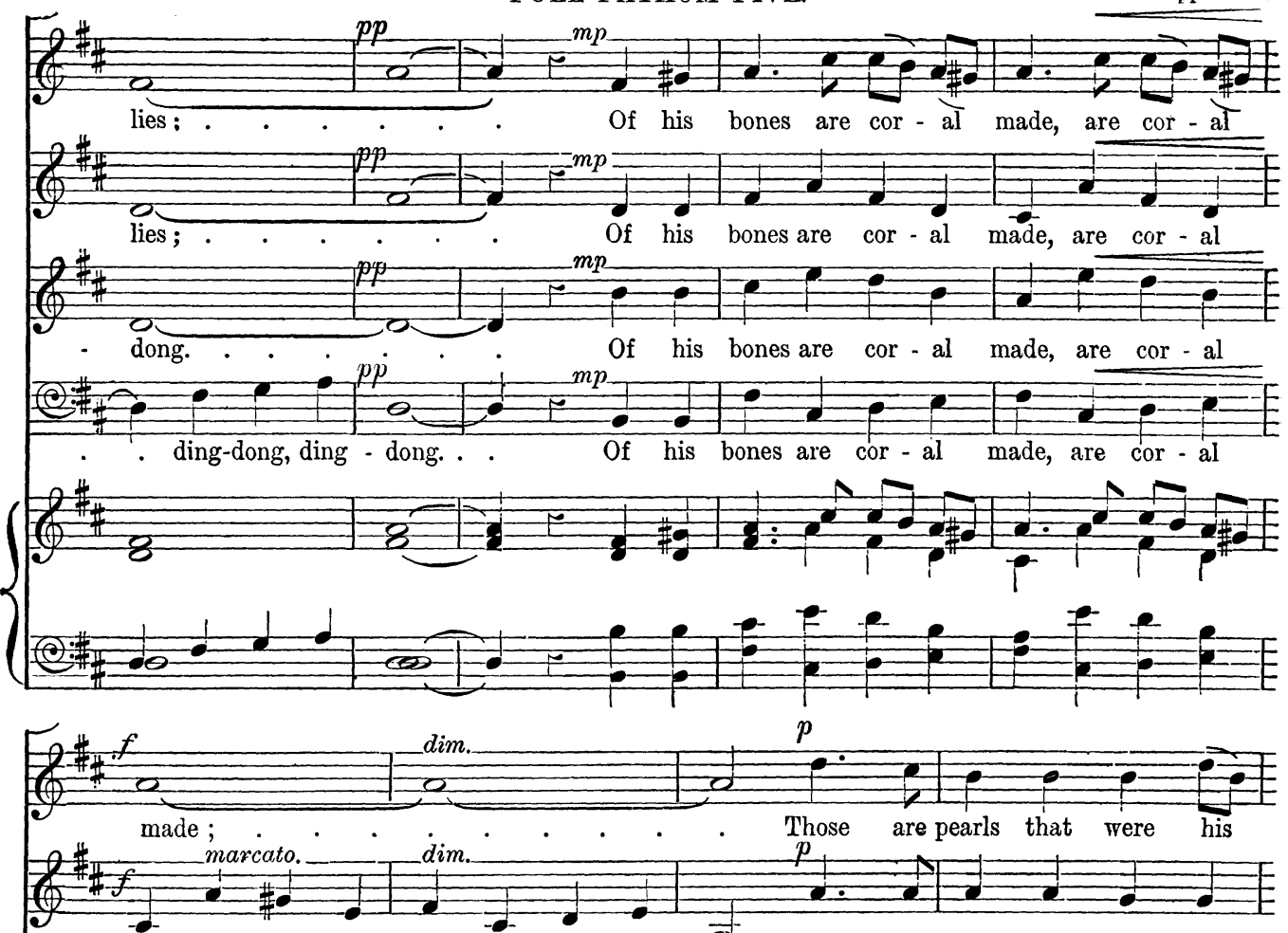

made;Ding-dong, ding - dong, ding-dong, ding - dong. Those are pearls that were his
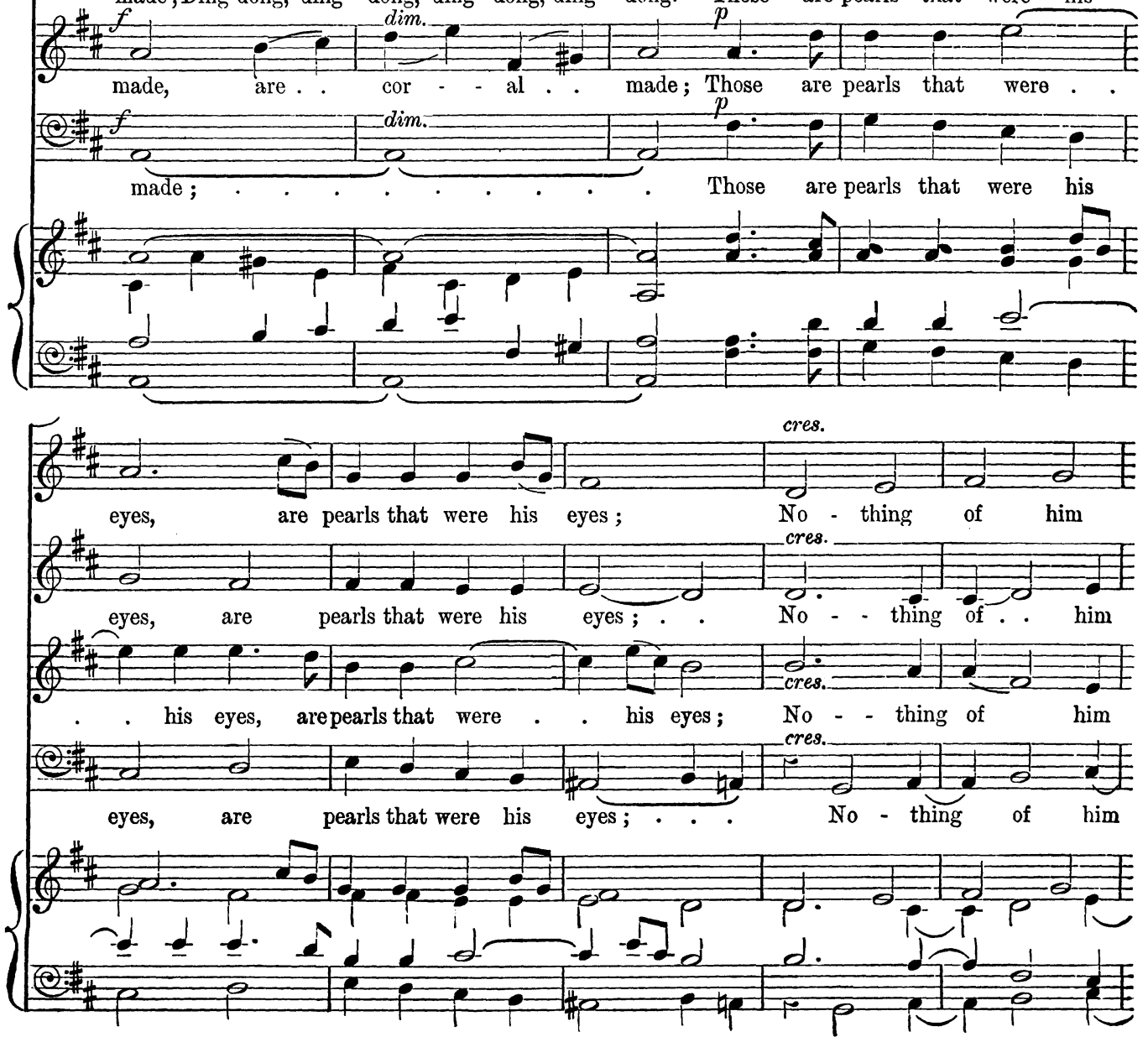

(2) 

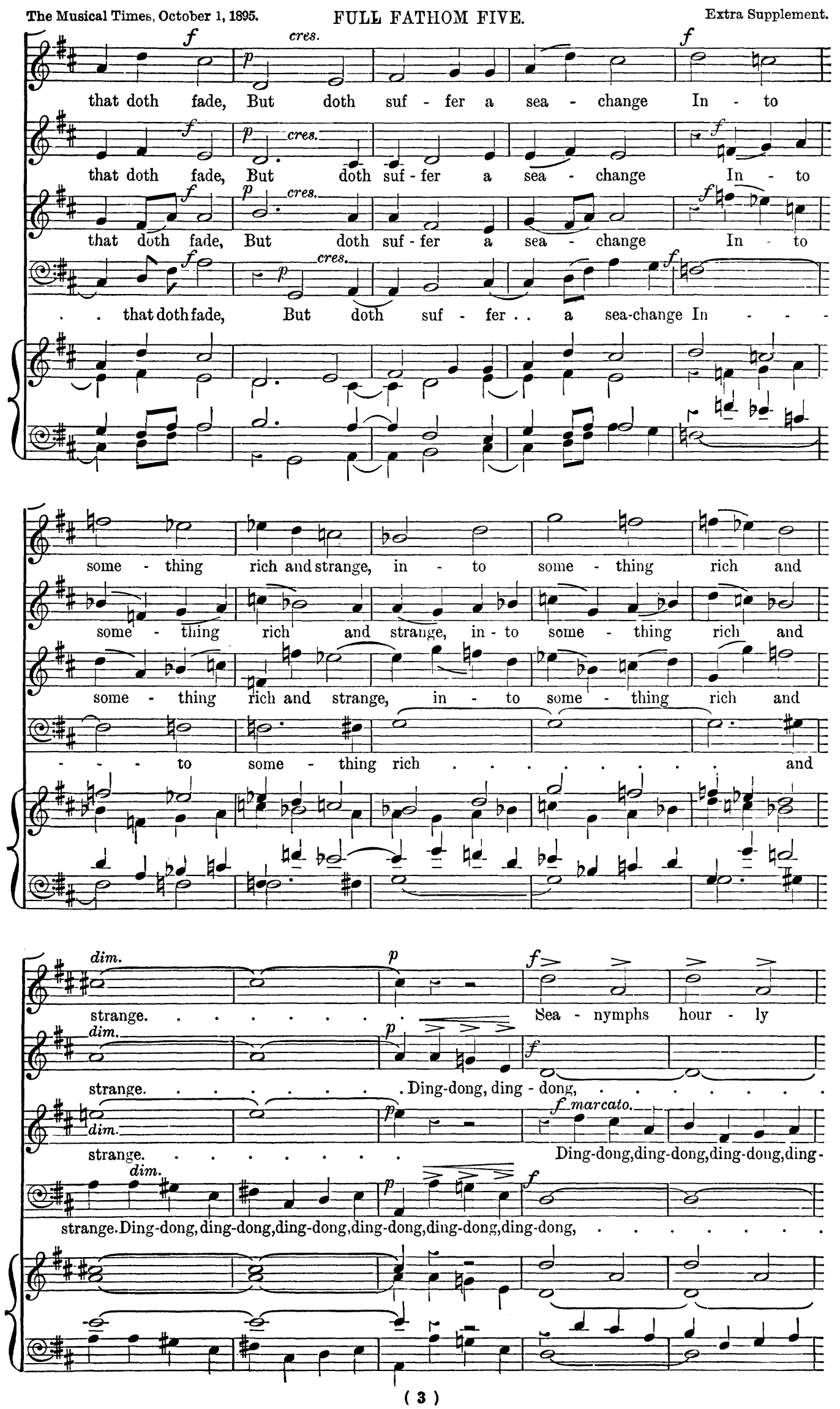
FULL FATHOM FIVE.
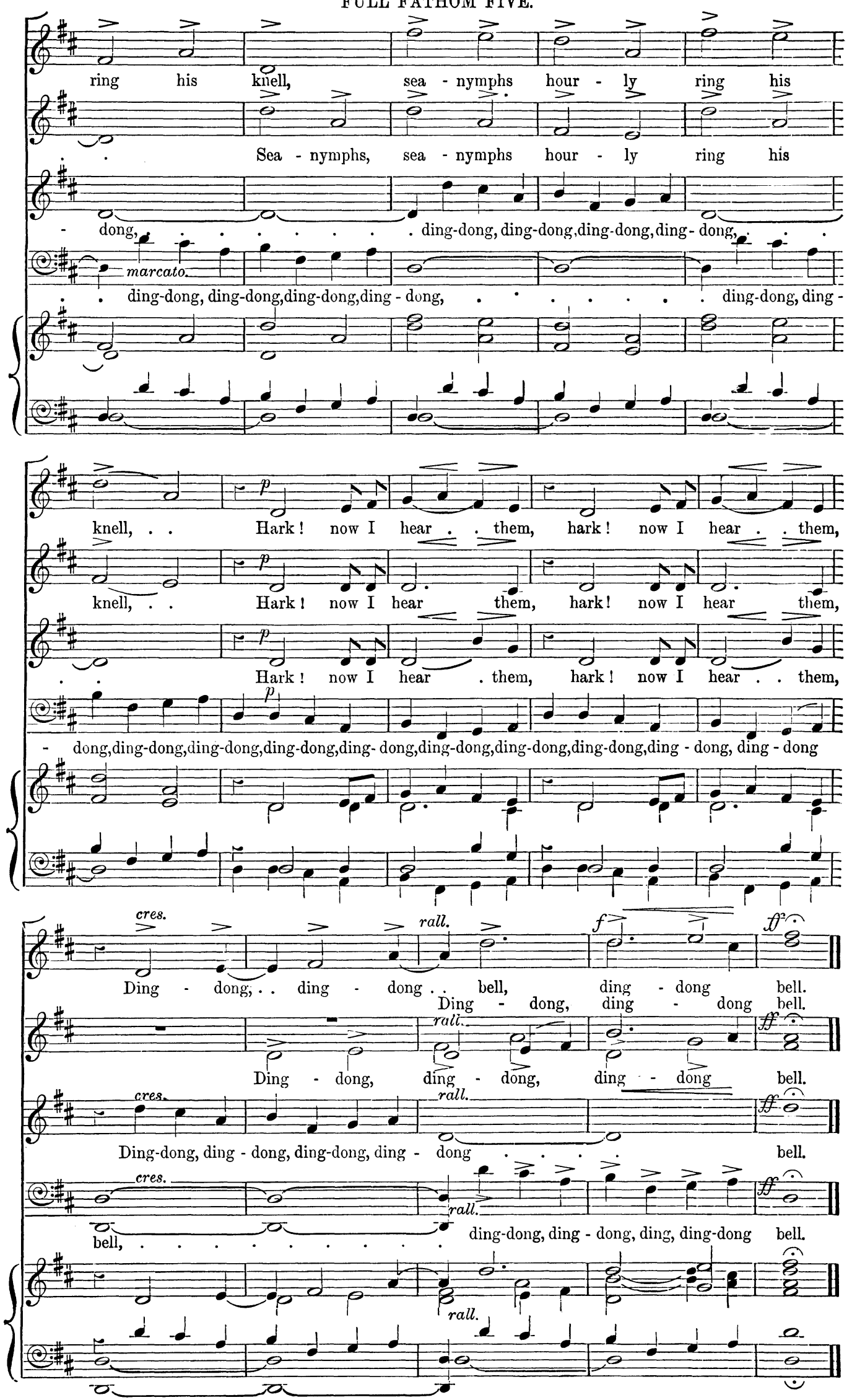

(4) 